\title{
Produções discursivas sobre o trabalho em equipe no contexto da reforma psiquiátrica: um estudo com trabalhadores de Centros de Atenção Psicossocial
}

\author{
Discursive productions about the teamwork in the \\ context of psychiatric reform: A study of workers \\ in Psychosocial Care Centers
}

Juliana Catarine Barbosa da SILVA

Pedro de OLIVEIRA FILHO²

\begin{abstract}
Resumo
O artigo objetiva analisar as produções discursivas de trabalhadores de Centros de Atenção Psicossocial sobre o processo de atuação em equipe. Adota-se como abordagem teórico-metodológica a Psicologia Social Discursiva, uma abordagem construcionista no contexto da Psicologia Social. A opção por centrar os estudos nos trabalhadores em saúde mental deve-se ao fato de que, no Brasil, esses profissionais foram os precursores do movimento de Reforma Psiquiátrica. A pesquisa, de natureza qualitativa, contemplou 14 entrevistas semiestruturadas com profissionais de dois Centros de Atenção Psicossocial da cidade de Recife (PE). Delimitação de lugares, diluição de saberes e necessidade de formação profissional foram sentenças recorrentes durante as entrevistas. As falas aqui analisadas revelam equipes que se encontram permeadas por conflitos, tensões e possibilidades de construção de suas práticas profissionais. Tais falas apontam para a necessidade de dar visibilidade e fomentar discussões sobre as referidas práticas.
\end{abstract}

Unitermos: Análise de discurso; Centros de Atenção Psicossocial; Interdisciplinaridade; Reforma psiquiátrica; Trabalho em equipe.

\begin{abstract}
This article aims to analyze the discursive productions of workers from the Psychosocial Care Centers about the process of team work. Adopts as theoretical approach the Discursive Social Psychology, a constructionist approach within the social psychology. The decision to focus our studies on professionals in mental health due to the fact that, in Brazil, these workers were the precursors of the Psychiatric Reform movement. Our research, qualitative, included 14 semi-structured survey with professionals from the Psychosocial Care Centers in the city of Recife (Pernambuco). Delimitation of seats, dilution of knowledge and need for training, these sentences were recurrent during the interviews. The reports reviewed here show teams that are permeated by conflicts, tensions and possibilities of construction of their professional practices. Such statements show the need of visualization and discussion of those practices.
\end{abstract}

Uniterms: Discourse analysis; Centros de Atenção Psicossocial; Interdisciplinarity; Psychiatric reform; Teamwork.

$\operatorname{rrv}$

1 Universidade Federal de Pernambuco, Programa de Pós-Graduação em Psicologia. R. Don Manoel de Medeiros, s/n., Dois Irmãos, 52171-900, Recife, PE, Brasil. Correspondência para/Correspondence to: J.C.B. SILVA. E-mail: <jucatarine@gmail.com>.

2 Universidade Federal de Campina Grande, Unidade Acadêmica de Ciências da Saúde. Campina Grande, PB, Brasil.

Artigo elaborado a partir da dissertação de J.C.B. SILVA, intitulada "Entre (des) encontros, tensões e possibilidades: reforma psiquiátrica e trabalho em equipe na cidade do Recife". Universidade Federal de Pernambuco, 2010. 
O presente artigo tem como foco a questão do trabalho em equipe na perspectiva de trabalhadores que atuam no contexto da Reforma Psiquiátrica. No Brasil, esses personagens foram os precursores das críticas ao sistema psiquiátrico tradicional e propuseram mudanças éticas, políticas e técnicas para a construção de novos lugares para as pessoas em sofrimento psíquico. Segundo Birman (1992), a reforma da Psiquiatria propõe a construção de um novo espaço social destinado à loucura, tornando necessário repensar e construir novos repertórios de atuação para os profissionais da saúde mental.

O interesse em compreender o trabalho na saúde mental sob o prisma da atuação em equipe justifica-se pela prioridade que é dada a esse tipo de atividade no processo de estruturação dos serviços substitutivos. No Brasil, a partir da década de 1970, diante das políticas de cunho racionalizador adotadas pelo setor de saúde, as equipes ganharam destaque como forma de alcançar os objetivos propostos pelas novas políticas de saúde. O Movimento da Reforma Sanitária, atrelado às propostas de mudança assistencial, conferiu às equipes o papel de consolidar as ações de integralidade e melhoria dos serviços (Costa, 2007).

Peduzzi (2001), com base em uma análise da literatura sobre o tema, distingue duas noções de trabalho em equipe. A primeira, denominada equipe agrupamento, seria caracterizada pela justaposição das ações, agrupamento dos agentes e fragmentação. A segunda, denominada equipe integração, recomendada pela proposta da integralidade das ações de saúde, seria caracterizada pela articulação das ações e interação entre os agentes. Ainda segundo Peduzzi (2001), o trabalho em equipe do tipo integrado é representado como o modelo ideal de trabalho para as práticas em saúde, tendo assumido um lugar de "tábua de salvação" para diversos conflitos entre os distintos atores e suas especialidades nas equipes multiprofissionais nos últimos anos.

Esses conflitos e tensões, indiscutivelmente, fazem parte do cotidiano das equipes profissionais no campo da Saúde e da Saúde Mental, como atestam diferentes pesquisas. Um estudo realizado por Campos (1997), no interior dos Centros de Atenção Psicossocial (CAPS) mineiros, mostra que a prática do trabalho em 610 equipe no contexto da Reforma Psiquiátrica é marcada por tensões e conflitos. Tensão e conflito foram detectados, igualmente, em estudo empírico realizado com uma equipe de um serviço ambulatorial de uma cidade nordestina. Nesse estudo, Severo e Dimenstein (2011) observaram a existência de conflito entre dois paradigmas de gestão e trabalho, o asilar e o psicossocial, que se assemelham à tipologia supracitada de Peduzzi (2001). O primeiro, hospitalocêntrico, apresenta as seguintes características: fragmentação das tarefas, pouco diálogo entre os profissionais, verticalização e poder decisório nas mãos dos médicos. O segundo, preconizado pela proposta de desinstitucionalização da Reforma Psiquiátrica, caracteriza-se pela cooperação, horizontalização e integração das ações.

Segundo Severo e Dimenstein (2011, p.347), a coexistência desses paradigmas "acaba gerando tensões no cotidiano do ambulatório, as quais indicam a verticalização do saber psiquiátrico, a hegemonia dos especialismos, a fragmentação dos processos de trabalho, dentre outros". O trabalho de Severo e Dimenstein apresenta evidências de que o paradigma hegemônico, o asilar, resiste ao avanço do paradigma psicossocial. Não obstante essas resistências, no campo da saúde mental, o paradigma da atenção psicossocial ganha força e trás com ele o modelo de interdisciplinaridade e sua proposta de horizontalização das relações intrainstitucionais como ideal de ação para as equipes de saúde mental. É a partir da proposta de atenção psicossocial que a noção de interdisciplinaridade adentra nos serviços substitutivos aos manicômios (Tavares, 2005).

Costa-Rosa, Luzio e Yasui (2001) ressaltam que o princípio da integralidade, que também permeia as práticas dos referidos locais, implica uma série de mudanças nas ações de seus trabalhadores, e essas mudanças são a base para a efetivação de um princípio de cidadania dos trabalhadores em saúde mental que seja coerente com a meta de singularização proposta pela reforma. Essa compreensão da realidade no contexto do adoecer psíquico trabalha com uma série de elementos que transcendem os limites da disciplinaridade. Nesse contexto, a prática interdisciplinar é fundamental para que possamos compreender as idiossincrasias da pessoa em sofrimento psíquico (Silva \& Tavares, 2003).

A respeito da saúde mental, Silva e Tavares (2003) ressaltam que as experiências de ação interdisciplinar são enfrentadas como um desafio, tendo em 
vista a gama de especialidades profissionais que estão envolvidas na prática psicossocial. Para os autores, as possibilidades de integração profissional permitem o exercício do pensamento complexo, que corresponde ao pilar de sustentação epistemológica do paradigma da atenção psicossocial.

Contudo, tendo em vista o universo multifacetado que envolve as práticas interdisciplinares em saúde, ainda temos muito a aprender. Muitas dificuldades teóricas e práticas são percebidas durante a efetivação desse processo. Penido (2002) afirma, por exemplo, que é comum observar o uso equivocado do termo interdisciplinaridade com o sentido de multiprofissionalidade pelas equipes de saúde mental. Isso levaria as equipes multiprofissionais a pressupor um exercício interdisciplinar, o que nem sempre ocorre.

Procurando compreender a natureza desse processo em nosso contexto e identificar possíveis tensões, conflitos e impasses no caminho, realizamos um estudo com o objetivo de identificar o significado do trabalho em equipe em produções discursivas de trabalhadores de saúde mental que atuam em Centros de Atenção Psicossocial da cidade do Recife (PE).

\section{Método}

A pesquisa, de natureza qualitativa, foi realizada em dois CAPS da cidade Recife. Nossa inserção nos serviços ocorreu após a autorização formal para a realização da pesquisa por parte da prefeitura da referida cidade. Os serviços foram visitados, inicialmente, com o objetivo de apresentar a pesquisadora e o projeto de pesquisa ao corpo técnico das instituições. O projeto foi recebido de forma satisfatória pela maioria dos profissionais e a gerência de cada serviço disponibilizou uma sala para que as entrevistas fossem realizadas. O momento de realização das entrevistas foi negociado individualmente com cada profissional, de forma que não interferisse na rotina de cada instituição.

Os serviços foram frequentados no período de maio a setembro de 2009 para a realização das entrevistas. Mesmo sem observações sistemáticas da rotina dessas instituições, foi possível perceber que elas apresentavam estruturas de funcionamento bastante distintas. No momento da pesquisa, o primeiro serviço, que funcionava nos turnos da manhã e da tarde, era formado por uma equipe mínima de profissionais, porém contava com um profissional de cada especialidade preconizada pelo projeto de funcionamento da instituição.

Já o segundo serviço encontrava-se, na ocasião da pesquisa, em precárias condições de funcionamento, contando apenas com seis técnicos que trabalhavam somente com os usuários já admitidos, e não realizava novas admissões. Segundo informações fornecidas pelos próprios funcionários, tais condições decorriam da não reposição dos trabalhadores que saíram da instituição.

Considerando as diretrizes para estudos com seres humanos, que normatizam a proteção dos direitos dos envolvidos na pesquisa, conforme os aspectos éticos indicados pela Resolução no 196/96 do Conselho Nacional de Saúde, as entrevistas foram realizadas somente depois que os participantes leram e assinaram o Termo de Consentimento Livre e Esclarecido.

Foram realizadas 14 entrevistas semiestruturadas, com duração aproximada de 40 minutos cada. Os seguintes profissionais foram entrevistados: um assistente social, três enfermeiras, uma auxiliar de enfermagem, dois educadores físicos, dois médicos psiquiatras, duas psicólogas e três terapeutas ocupacionais. Dentre os entrevistados, apenas dois eram do sexo masculino: um médico psiquiatra e um educador físico. No que diz respeito aos anos de experiência profissional, os entrevistados variavam entre quatro e dezoito anos de experiência. Aos entrevistados foram atribuídos nomes fictícios com o objetivo de manter em sigilo suas identidades.

A pesquisa adotou como abordagem teórico-metodológica a Psicologia Social Discursiva, uma abordagem construcionista que desenvolve uma técnica específica de análise de discurso em Psicologia Social. Sua perspectiva tem como foco principal compreender a forma como as pessoas descrevem, explicam e significam o mundo em que vivem e as consequências dessas práticas discursivas (Potter, 1998; Potter \&Wetherell, 1987; Wetherell \& Potter, 1992).

Antes da análise propriamente dita, todas as entrevistas foram transcritas, com o cuidado de preservar ao máximo a forma como os participantes falaram (incluindo as marcas discursivas de pronúncia e as pausas). 
Após a transcrição, foram realizadas leituras cuidadosas do material discursivo com o objetivo de torná-lo mais familiar aos analistas. A codificação, na perspectiva teórico-metodológica adotada, constitui apenas uma análise preliminar, cujo objetivo é organizar os dados brutos em categorias para análises mais aprofundadas (Gill, 2002; Potter \& Wetherell, 1987). A análise dispensa uma atenção especial ao modo como os sujeitos entrevistados mobilizam sistemas de significação para realizar ações específicas, construir versões de ações, do eu e das estruturas sociais. Evita-se também aprofundar no modo como os sujeitos mobilizam recursos discursivos para apresentar suas versões como fatos objetivos, e não como meras versões da realidade construídas a partir de uma perspectiva limitadamente subjetiva (Potter, 1998; Potter \& Wetherell, 1987; Wetherell \& Potter, 1992).

\section{Resultados e Discussão}

Os relatos dos entrevistados sobre o trabalho em equipe nos serviços substitutivos foram divididos em duas categorias: 1) relatos que retratam de forma positiva essa forma de trabalho, e 2) relatos que a retratam de forma negativa, descrevendo-a como um elemento que apaga os limites das diferentes especialidades. Esses últimos relatos, predominantes na amostra (e organizados de maneira mais cuidadosa e complexa por adotarem um posicionamento ideológico contrário ao que oficialmente rege os serviços substitutivos), serão analisados mais demoradamente nas páginas que se seguem.

\section{O elogio da interdisciplinaridade}

Somente dois dos participantes entrevistados para essa pesquisa (um deles, José, ${ }^{3}$ médico psiquiatra, respondendo a um questionamento sobre o modo de funcionamento da equipe, e a outra, Marta, educadora física, respondendo a um questionamento sobre as relações entre os técnicos) retrataram de maneira claramente positiva a forma de trabalho em equipe preconizada pelos serviços substitutivos.
José - psiquiatra: Um momento muito rico, porque a gente tem oportunidade de trocar ideias com profissionais de outras áreas, ver o ponto de vista da terapia ocupacional, do serviço social, da enfermagem, não é? Da psicologia, não é? E... resolver conflitos, ou pelo menos tentar diminuir esses conflitos existentes na equipe, porque isso é natural, no trabalho, não é? Multiprofissional, não é? Que ocorram essas dúvidas... . A visão de um é pela admissão, isso acontece com muita frequência.

Marta - educadora física: ...eu não sei o quê que acontece no grupo de psicologia. Entendeu? Então, eu acho que ajudaria muito se fosse, se tivesse essa maior interação. Esse lado da profissão. Porque se diz "uma equipe multidisciplinar". Éuma equipe que se reúne uma vez por semana para falar de vários casos, são quatro horas, mesmo assim não dá tempo para falar de todos os casos. E fica cada um meio assim na sua área, né? ...na hora realmente da prática cada um na sua área.

Embora reconheça a existência de conflitos, José afirma que o trabalho em equipe de natureza multiprofissional é "um momento muito rico", que possibilita o diálogo entre as diferentes áreas. Em sua fala, o termo "multiprofissional" nomeia um conjunto de práticas geralmente associadas ao conceito de interdisciplinaridade, próximo ao desenvolvido por Vasconcelos (2002), que define a interdisciplinaridade como uma estrutura horizontal que tende a restringir as relações de poder entre as distintas disciplinas, prevalecendo a reciprocidade e o enriquecimento mútuo.

Marta, assim como José, posiciona-se positivamente em relação à interação dos técnicos em uma equipe de saúde mental, que ela denomina "multidisciplinar". Ela destaca, no entanto, uma contradição no interior do grupo, pois afirma que sua equipe é multidisciplinar, mas não consegue interagir e trocar saberes. Como José, a educadora física descreve um conjunto de práticas associadas ao conceito de interdisciplinaridade, práticas que, diferentemente daquilo que afirma José, não fariam parte do cotidiano da equipe. Marta e José fazem parte da mesma equipe; contudo, apresentam relatos distintos e contraditórios sobre o modo como ela funciona.

\section{$\leadsto r$}

6123 Todos os nomes dos participantes da pesquisa foram substituídos por nomes fictícios com o objetivo de preservar o sigilo sobre suas identidades. 


\section{Interdisciplinaridade e perda da identidade profissional}

Como afirmado anteriormente, a maioria dos participantes retratou de maneira negativa o trabalho em equipe do tipo "interdisciplinar" ou "multiprofissional". Isso foi feito, algumas vezes, de maneira aberta, ou de maneira muito sutil. Mas em todos os argumentos desses participantes o tema da perda da identidade profissional esteve presente. Esse tema apresenta-se na fala de Marina, em resposta a um questionamento sobre o trabalho do enfermeiro em saúde mental:

Marina - enfermeira: O trabalho do enfermeiro na saúde mental ele fica meio que... diluído com... como a gente trabalha em equipe fica uma coisa meio que diluída. Especificamente do enfermeiro não aparece muita coisa, mais a questão da medicação, dos cuidados que a gente tem que ter com qualquer paciente, mas que não só o enfermeiro tem, os outros técnicos também passam a ter como é uma coisa meio, é muito, muito... interdisciplinar, né? ...é meio que misturado, as funções, a gente é... faz um trabalho um pouco do psicólogo, um pouco de assistente social, um pouco do médico, um pouco de tudo, nem sempre tem todos os profissionais presentes na equipe.

Marina constrói um relato no qual a atuação de sua profissão, Enfermagem, ainda não está clara e bem definida no contexto das equipes de saúde mental do CAPS. Um relato no qual a identidade da enfermeira se dilui e em que os limites, as atribuições e as especificidades de cada profissão tornam-se opacos. Aquilo que era atribuição do enfermeiro também é feito por outros profissionais. Por outro lado, o enfermeiro passa a fazer "um pouco" do trabalho do psicólogo, do médico, do assistente social etc. Tudo se mistura nesse contexto. Embora não o diga explicitamente, há uma tácita desaprovação da forma de organização dos CAPS em seu discurso. Várias passagens indicam essa desaprovação, mas a passagem na qual isso se torna mais claro é quando, com evidente ironia, Marina afirma que o trabalho em equipe no CAPS é [“... uma coisa... muito, muito... interdisciplinar"].

O relato de Camila (também enfermeira, porém não pertencente ao mesmo serviço de Marina), produzido quando a entrevistadora Ihe solicitou a descrição do funcionamento da equipe no serviço, retrata um contexto marcado pelo incômodo resultante da falta de limites entre os espaços de atuação de cada profissional.

Camila - enfermeira: Agora assim, uma coisa que eu sempre tenho cuidado é isso: me policiar para não entrar no espaço do outro, porque às vezes, eu acho que o pessoal perde essa noção. ... Aqui é tão... . Que se você não tiver cuidado você entra. Eu mesma, eu sou muito fácil de entrar no de C. [psiquiatra], eu passei quinze anos no hospital, eu sei muito de medicação. ... Até com a prática você aprende e assim, eu tenho muito esse cuidado, sabe? Eu já vi tanto psiquiatra ir embora, justamente por isso. Eu acho que se o pessoal... . Tem psiquiatras muito bons que se você falar do CAPS, o CAPS é uma peste para eles. Eles não aguentam essa coisa de questionar, questionar. Não sei por que diacho tem os psicólogos que gostam tanto de questionar diagnóstico de médico. Éuma coisa que não me incomoda, se ele errar é problema dele, não é meu. Aqui já teve casos de um psicólogo suspender a medicação de paciente... não é? Foi isso que fez os psiquiatras debandarem. Eu acho que a gente tem que respeitar, não é?

Aqui é importante destacar as estratégias discursivas utilizadas por Camila para construir a ideia de que a interdisciplinaridade pode produzir conflitos entre os distintos especialistas nos CAPS. A profissional inicia assim sua fala: "Agora assim, uma coisa que eu sempre tenho cuidado é isso: me policiar para não entrar no espaço do outro, porque às vezes, eu acho que o pessoal perde essa noção". Antes de lançar a acusação sobre os membros da equipe que "perdem a noção", ela já se posiciona como aquela pessoa que procura não fazê-lo. A enfermeira relata a interferência de alguns profissionais nas especificidades de seus companheiros de equipe, ressaltando que tais interferências resultaram em brigas e até mesmo na saída de membros do grupo.

Camila, antes de posicionar algumas categorias profissionais - "os psicólogos" -, no lugar daqueles que interferem na seara de atuação de outras especialidades e que não conhecem o seu lugar, posiciona-se como alguém que, mesmo tendo mais propriedade que esses para fazê-lo - "Eu mesma, eu sou muito fácil de entrar no de C. (psiquiatra), eu passei quinze anos no hospital, eu sei muito de medicação" -, não o faz.

Camila relata que os psiquiatras não suportam os constantes questionamentos no CAPS: "Eles não 
aguentam essa coisa de questionar, questionar". Ao apoiar a não aceitação dos questionamentos por parte dos profissionais médicos, a enfermeira também se coloca contra o próprio sistema reformista, que apoia a dissolução das hierarquias nos serviços; hierarquias que ela defende com um discurso que pode ser lido como uma defesa veemente do sistema tradicional presente nos hospitais.

A enfermeira coloca-se contra as interferências e invasões das especialidades e ressalta que "...se ele errar é problema dele...". Tal sentença, além de refletir a necessidade de que as atribuições sejam delimitadas, também questiona, implicitamente, a ideia de que atividades partilhadas devem implicar em responsabilidades partilhadas. Em seu discurso, o saber médico aparece em destaque e o profissional de medicina é colocado no lugar daquele que não pode e nem deve ser questionado.

Seguindo a mesma linha argumentativa de Marina e Camila, a fala de Rita, abaixo, produzida em resposta a uma pergunta sobre a relação entre os técnicos, desenvolve a ideia de que as possibilidades de interferência, ou mesmo sobreposições de papéis, gerariam tensões e incômodos entre os membros da equipe:

Rita - psicóloga: ...eu não participei, mas semana passada parece que teve um lance desse aí. A enfermeira parece que foi participar... apresentar um caso dela se eu não me engano de... um caso já antigo aqui... e ela foi internada. E ela colocou essa questão que estava cuidando com muita dificuldade, cuidando dela. Embora, assim, por ela trabalhar no Ulysses, ela também tem uma visão de lá... . Então, acha que muitas coisas de lá é correto agir aqui também. Então, eu acho que falta um pouquinho assim... em relação à profissão dela, ela é enfermeira, ela não é psicóloga. Então, ela tava fazendo um acompanhamento como se fosse uma psicóloga. Escutando, tentando e dizendo, mas da forma dela - 'faça assim, faça assim, faça assado', talvez ela estivesse tomando partido.

Potter (1998) afirma que, ao produzir um discurso, as pessoas utilizam uma série de recursos para anular ou minimizar as possíveis implicações negativas para elas próprias daquilo que afirmam, recursos denominados "vacinas" pelo autor. Rita procura deixar claro que seu relato é de segunda mão e não o relato de um 614 evento que ela própria presenciou: "eu não participei, mas semana passada parece que teve um lance desse aí". Ao iniciar seu relato dessa maneira, a entrevistada passa a narrar acontecimentos por cuja veracidade não pode se responsabilizar.

Na narrativa desenvolvida por Rita, a possibilidade de uma ampliação no leque de intervenções de um determinado profissional é logo interpretada como invasão à especificidade de outra disciplina. Em sua descrição, procura posicionar-se como alguém que não se preocupa com a "falta de identidade" supostamente presente no espaço do CAPS, e posiciona sua colega enfermeira como alguém que não sabe realizar seu trabalho de forma correta. Ou seja, seu posicionamento é o de não se incomodar com a intersecção de saberes. Em seguida, ela descreve um episódio que parece alertar para os perigos que podem advir dessa indefinição de papéis. Sua descrição põe em questionamento as habilidades da outra profissional ao apresentá-la como alguém que levou uma usuária antiga do serviço a ser internada novamente, afirmando que aquela profissional, por também atuar em um serviço de características manicomiais, traz resquícios do outro espaço para o serviço substitutivo.

A fala de Karla, produzida em resposta a um questionamento sobre as relações entre as diferentes especialidades profissionais na equipe, destaca, assim como a de Rita, os incômodos decorrentes da ausência de delimitação de funções, como se os mesmos não Ihe dissessem respeito. A entrevistada narra acontecimentos, fala de incômodos, reproduz falas de outros profissionais e relata situações de tensão, mas a maneira como articula seu discurso revela uma pessoa não diretamente implicada nas ações descritas:

Karla - terapeuta ocupacional: E hoje o pessoal está
reclamando demais disso, muitos profissionais de CAPS
hoje reclamam da falta de especificidade, que teve um
tempo em que se disse: 'O profissional do CAPS é um
técnico em saúde mental. Então, todo mundo vai fazer
tudo'. Então, começou com essa coisa que se perdia
muito da especificidade, não é? Mas, isso pelo que a
gente tem feito, pelo que a gente vem percebendo,
causa um incômodo. É do enfermeiro que diz: 'Mas, eu
não sou psicólogo.' 'Eu não posso estar fazendo isso, eu
não posso estar fazendo aquilo'. Então, é difícil você
traçar uma linha. ... A proposta quando você diz que
vai discutir um caso, que vai compartilhar, eu acho que
passa por um respeito ao trabalho do outro. Eeu percebi 
que você pode contribuir e no final tirar um todo. Eisso é difícil, principalmente a gente tendo a formação que tem, é muito difícil.

Trata-se de uma estratégia narrativa que se aproxima do que Potter (1998) caracteriza como "descrição vívida". Nesta forma de argumentação, o falante utiliza uma série de detalhes contextuais e acontecimentos para criar a impressão de que observa o contexto "em volta" a partir de um olhar singular.

Nesse sentido, sua postura é de distanciamento. Não se posiciona de maneira clara em relação àquilo que descreve. Não é Karla que tem reclamações em relação ao modelo, são os outros que reclamam: "hoje o pessoal está reclamando". Não é ela que está incomodada, mas o que ela vê ao seu redor indica o incômodo: "pelo que a gente vem percebendo, causa um incômodo". Karla assume a postura de quem faz um relato fiel do cotidiano do CAPS, um relato realista de alguém que simplesmente observa aquilo que ocorre. Como resultado, a crítica sutil ao novo modelo aparece em sua fala como uma avaliação ponderada das dificuldades no caminho de uma nova prática, dificuldades que teriam relação com a própria formação dos técnicos.

A fala de Isabel, em resposta ao questionamento sobre o trabalho em equipe no serviço, aproxima-se da fala de Karla em relação ao tom de distanciamento adotado:

Isabel - enfermeira: ...no CAPS é bem diferente, inclusive há muito questionamento no CAPS, a essa questão da especificidade, tem técnico que ele cobra muito isso... aí assim, ele não admite, por exemplo, ele ser um psicólogo, um terapeuta ocupacional e estar lá na... dentro de uma farmácia, mesmo que esteja a medicação tudo organizado, mas ele pegar e dar a alguém, porque ele acha que isso aí não tem nada a ver com a área específica dele. Já outras pessoas acreditam que trabalhar em equipe é trabalhar dessa forma, que o CAPS tem que de... de... de... entendimento de funções.

(E): Evocê como é que vê isso?

(I): Às vezes, de forma muito ambivalente, porque a minha existe... existe um código de ética que ele é muito preciso, né? Ela... ele na hora que a lei vem ela não... ela não quer saber de subjetivo, ela vem, e ela vem e enquadra você. Por outro lado, da forma que é dentro deste modelo sei que não teria como funcionar com muita rigidez, certo? Então, vocêfica muito ambivalente quando você vê uma pessoa provar matematicamente que ela pode se comprometer, se ela for fazer determinada função e por outro, você... se a gente começa com tanta rigidez será que a gente não vai terminar novamente no manicômio?

Contudo, em sua fala, observa-se um elemento novo. Quando a entrevistadora a questiona no intuito de que ela se posicione em relação à situação descrita, Isabel demonstra não ter opinião definida sobre a temática em questão. Coloca argumentos contra, expõe ideias a favor, dá voz à opinião de terceiros; define-se, enfim, como alguém que tem uma posição ambivalente em relação à questão.

A tentativa de não se comprometer com quaisquer posicionamentos fica evidente quando ela faz uso de uma categoria de crédito (Potter, 1998) - no caso, o código de ética -, para apoiar o argumento de que ele delimita melhor as funções. Não é ela, Isabel, quem afirma que é preciso haver delimitação entre as funções profissionais: é o código de ética.

As profissionais cujas falas foram analisadas neste item usam diferentes estratégias discursivas, evitando ser criticadas por se alinharem a um modelo atrasado e conservador. Elas combatem, sutilmente, o modelo interdisciplinar de atuação em equipe, que orientou ideologicamente a criação dos serviços substitutivos em que atuam.

O discurso sobre perda de identidade profissional, mobilizado por elas como forma de resistência ao modelo interdisciplinar, não é um fato isolado, presente somente entre esses profissionais que trabalham nos serviços substitutivos na capital pernambucana; é encontrado também em outras pesquisas acadêmicas sobre esses serviços (Campos, 1997; Vasconcellos, 2010). Na pesquisa de Vasconcellos, realizada em um CAPS no Rio de Janeiro (RJ), algumas passagens das entrevistas realizadas com os profissionais são muito semelhantes às encontradas na pesquisa descrita no presente artigo.

Em estudo realizado por Abuhab, Santos, Messenberg, Fonseca e Aranha e Silva (2005), em um CAPS, o discurso sobre a perda da identidade profissional não se apresentou de forma explícita; no entanto, os profissionais (psiquiatras, enfermeiros, psicólogos) foram enfáticos ao apontar as dificuldades 
para integrar de fato a equipe. Dentre essas dificuldades, os profissionais citam a resistência das diferentes categorias profissionais quando se trata de analisar os transtornos dos usuários com um olhar interdisciplinar. Os profissionais não médicos citam, principalmente, a resistência dos psiquiatras à integração e a hegemonia desses profissionais no serviço.

Dois trabalhos realizados com enfermeiros indicam que, no caso específico dessa categoria, o especialismo, o corporativismo e o alinhamento com o modelo asilar podem ter relação com essa resistência. Castel (1987) afirma haver, desde as propostas trazidas pela psiquiatria de setor, uma forte oposição por parte dos profissionais de enfermagem à atuação em espaços extra-hospitalares. $O$ autor ressalta ainda que, na ocasião da proposta dos setores, alguns sindicatos de enfermagem chegaram a se opor oficialmente "à supressão dos leitos hospitalares em defesa do 'instrumento de trabalho' de sua categoria"(p.57). No Brasil, Silva et al. (2004) constataram, pelas entrevistas com estudantes do último ano de enfermagem de uma universidade federal do nordeste brasileiro, a solidariedade entre o saber da Enfermagem e o saber da Psiquiatria tradicional no contexto dos serviços substitutivos.

\section{Considerações Finais}

Os elementos expostos neste artigo revelam equipes permeadas por conflitos, tensões e possibilidades de construção de suas práticas profissionais. Os trabalhadores entrevistados apresentam relatos que tratam de suas experiências no contexto da saúde mental e das dificuldades relacionadas à prática interdisciplinar.

Nesses relatos, predominou o pensamento de que o trabalho em equipe nos serviços substitutivos aparece como um elemento diluidor das especificidades de cada profissional, como produtor de confusão e de perda da identidade profissional. São relatos que defendem, de maneira taxativa, a necessidade de delimitação dos espaços profissionais. A questão dos limites entre as especialidades apareceu nas falas dos entrevistados sob diversas perspectivas, e a invasão do espaço de atuação dos especialistas foi recorrente nas descrições de situações conflituosas.

Nesse contexto, ressaltam-se as precárias condições nas quais se encontravam os serviços visitados e o número escasso de profissionais. Tal situação aponta para a falta de cuidado das políticas públicas para com os serviços, elemento que tem implicações diretas para a qualidade do trabalho oferecido.

O discurso da valorização da especialização, recorrente de forma direta ou indireta na fala da maior parte dos profissionais entrevistados, mostra o quanto o modelo positivista da estratificação do conhecimento ainda persiste em nossos campos de trabalho. Outro elemento desse contexto é o processo de formação profissional mencionado por alguns trabalhadores e que recorrentemente aparece no debate sobre interdisciplinaridade.

Conclui-se que os cursos de graduação em saúde, em sua maioria, são marcados por pouco diálogo entre as disciplinas e pela fragmentação de saberes.

\section{Referências}

Abuhab, D., Santos, A. B. A. P., Messenberg, C. B., Fonseca, R. M. G. S., \& Aranha e Silva, A. L. (2005). O trabalho em equipe multiprofissional no CAPS III: um desafio. Revista Gaúcha de Enfermagem, 26(3), 369-380.

Birman, J. (1992). A cidadania tresloucada: notas introdutórias sobre a cidadania dos doentes mentais. In B. Bezerra \& P. Amarante (Orgs.), Psiquiatria sem hospício: contribuições ao estudo da reforma psiquiátrica (pp.71-90). Rio de Janeiro: Relume-Dumará.

Campos, G. V. (1997). Subjetividade e administração de pessoal: considerações sobre nodos de gerenciar trabalho em equipes de saúde. In E. E. Merhy, R. Onocko (Orgs.), Agir em saúde: um desafio para o público (pp.229-266). São Paulo: Hucitec.

Castel, R. (1987). A gestão dos riscos: da antipsiquiatria à pós-psicanálise. Rio de Janeiro: Francisco Alves.

Costa, R. P. (2007). Interdisciplinaridade e equipes de saúde: concepções. Mental, 8(8), 107-124.

Costa-Rosa. A., Luzio, C. A., \& Yasui, S. (2001.) As conferências nacionais de saúde mental e as premissas do modo psicossocial. Saúde em Debate, 25(58), 12-25.

Gill, R. (2002). Análise do discurso. In G. Gaskell (Ed.), Pesquisa qualitativa com texto, imagem e som (pp.244-270). Petrópolis: Vozes.

Peduzzi, M. (2001). Equipe multiprofissional de saúde: conceito e tipologia. Revista de Saúde Pública, 35(1), 103-109.

Penido, C. M. F. (2002). Embustes 'interdisciplinares': da especialização à polivalência: contribuições a partir do campo da saúde mental. In GIBS: Grupo Interdisciplinaridade na Saúde (pp.1-4). Recuperado em setembro 27, 2009, disponível em <http://www.hc.ufmg.br/gids/ 
textos_seminarios/os_riscos_da_interdisciplinaridade. $\mathrm{pdf}>$.

Potter, J. (1998). Representing reality: Discourse, rhetoric and social construction. London: Sage.

Potter, J., \& Wetherell, M. (1987). Discourse and social psychology: Beyond attitudes and behavior. London: Sage.

Severo, A. K., \& Dimenstein, M. (2011). Processos de trabalho e gestão na estratégia de atenção psicossocial. Psicologia e Sociedade, 23(2), 340-349.

Silva, J. P. L., \&Tavares, C. M. M. (2003). Educação permanente de profissionais de saúde mental: competências para o trabalho interdisciplinar. Saúde em Debate, 27(65), 290-301.

Silva, A. T. M., Souza, J. S., Silva, C. C., Nóbrega, M. M. L., Oliveira Filha, M., Barros, S., et al. (2004). Formação de enfermeiros na perspectiva da reforma psiquiátrica. Revista Brasileira de Enfermagem, 57(6), 675-678.

Tavares, C. M. M. (2005). A interdisciplinaridade como requisito para a formação da enfermeira psiquiátrica na perspectiva da atenção psicossocial. Texto e Contexto - Enfermagem, 14(3), 403-410.

Vasconcelos, E. M. (2002). Serviço social e interdisciplinaridade: o exemplo da saúde mental. In E. M. Vasconcelos. Saúde mental e serviço social: o desafio da subjetividade e da interdisciplinaridade (2a ed., pp.35-67). São Paulo: Cortez.

Vasconcellos, V. C. (2010). Trabalho em equipe na saúde mental: o desafio interdisciplinar em um CAPS. SMAD, Revista Eletrônica Saúde Mental Álcool Drogas, 6(1), 1-16. Recuperado em novembro 28, 2013, disponível em <http:/ /www.redalyc.org/pdf/803/80313414015.pdf>.

Wetherell, M., \& Potter, J. (1992). Mapping the language of racism: Discourse and the legitimation of exploitation. Hemel Hempstead: Harvester Wheatsheaf.

Recebido em: 11/8/2011

Versão final em: 18/3/2013

Aprovado em: 22/4/2013 
